\section{Endangered Species. $\dagger$}

To ensure that endangered species in Canada receive proper attention, the Department provides a secretariat for the Committee on the Status of Endangered Wildlife in Canada. That Committee, begun in 1977, furnishes information on flora and fauna regarded, on the best scientific

$\dagger$ CITES, the Secretary-General of which happens to be a Canadian.-Ed. evidence, as at risk. I wish to thank you for your continuing interest in our work.

[Signed: Yours sincerely, etc.]

Suzanne Blais-Grenier, Minister Environment Canada

Ottawa

Ontario $\mathrm{K} 1 \mathrm{~A}$ OH3

Canada.

\title{
US Pledges Support for UNEP and Observes World Environment Day
}

The United Nations Environment Programme (UNEP) ended its 13 th Annual Governing Council meeting in Nairobi, Kenya, on 24 May 1985. Delegates to the "businesslike' session did not dwell on extraneous political or regional concerns but instead worked harmoniously to move the UNEP secretariat towards a carefully-thoughtout and integrated programme.

Shortly before the opening of the meeting, the US delegation received administration approval to announce the US pledge of $\$ 10$ millions towards this year's UNEP budget of about US \$35 millions. Each year, the Reagan administration has sought to cut the US contribution, which in recent years has been restored by Congress to the usual $\$ 10$ million pledge. This year's pledge was restored thanks to the efforts of environmentalists, including Sierra Club members, and congressional supporters of UNEP, in particular Representative David Obey (D-Wisconsin). Rep. Obey successfully fought administration efforts to cut this year's Fiscal Year 1985 budget by $\$ 5.4$ millions and to give these funds to the International Atomic Energy Agency.

At the Governing Council meeting, the US promoted priority action and programme focus on: the GEMS (Global Environmental Monitoring System) and the new GRID (Global Resources Information Database); regional seas; desertification; International Registry of Potentially Toxic Chemicals; and environmental law and education. The environmental law programme of UNEP, the US, and others, stressed needs to continue to work on standards relating to ozone, hazardous wastes and chemicals, land-based marine pollution, and environmental impact assessment.
On World Environment Day, June 5th - a day designated by the United Nations for people everywhere to celebrate and reaffirm their dedicatioin to preserving the environment - the North American office of UNEP honoured individual and community initiatives. Young people who have worked in the California Conservation Corps and the Katimavik (the Eskimo word for 'meeting place')-the volunteer Canadian Youth Service-as well as Joseph P. Kennedy II, the Goodyear Tire and Rubber Company, and the Mayor of Akron, Ohio, were among those who received awards from the UN Secretary-General and UNEP's Excutive director. Two Canadians were also recipients: David Suzuki, for his nature series on Canadian television, and Senator H.O. Sparrow, for soil conservation.

A special award was presented to the Academy of Science of the USSR for preserving the beauty, purity, and wildlife, of Lake Baikal, the deepest and volume-wise largest freshwater lake in the world. Another award went to the Talavaya Center, which perpetuates the genetic diversity of native southwest agricultural crops by utilizing centuries-old farming methods practiced by the Talavaya Indians. Many Sierra Club supporters from the New York metropolitan area were invited to join in the celebration.

Patricia J. Scharlin, Director Sierra Club International Earthcare Center 228 East 48th Street

New York

NY 10017, USA.

\section{Identification of Largest Known Structure in the Universe - an Assemblage of Galaxies}

Astronomers have identified the largest known structure in the universe, an assemblage of galaxies and clusters of galaxies more than one thousand million light-years in length. The largest previously-reported similar structure, called a 'filament', was an assemblage or association of galaxies about 700 million light-years long, discovered in November 1982. A light-year is the distance that light travels in a year at a speed of 186,000 miles $(297,600 \mathrm{~km})$ per second-about six trillion miles in US terminology.

The newly-discovered system of galaxies was found in the northern region of the sky by Dr Jack O. Burns, an Associate Professor of Astronomy, and David J. Batuski, a graduate student, at the University of New Mexico. The large 'filament' is in the direction of two constellations, Perseus and Pegasus, and lies beyond 200 million lightyears from Earth.

The detection and study of such superclusters of galaxie is helpful to astronomers trying to learn more about the evolution of the universe. One group holds that galaxies were formed when supercluster-sized clouds of gas fragmented and condensed. Another school holds that relatively small galaxy-size structures formed first and then clustered as gravitational forces took hold and drew them together as the universe aged.
'We feel quite strongly that our data favour the model in which the superclusters formed first and galaxies later fragmented from supercluster clouds,' Dr Burns told the NSF. 'With such a model, the universe must be dominated by some form of dark or unseen matter, such as the exotic particles predicted recently by high-energy physicists.'

Dr Burns explained that, in order for structures of this size to be formed, more gravitational force, and therefore more mass, is needed than is present in luminous matterstars and galaxies. 'Therefore,' he said, 'we must postulate the existence of a dominant component of the universe consisting of non-luminous matter.'

The New Mexico astronomers used an Intensified Image Dissector Scanner-an electronic spectrograph-on the National Optical Astronomy Observatories' 84-inches (2.1-metres) telescope on Kitt Peak in Arizona. The spectrograph allowed them to determine distances of the galaxies and, therefore, three-dimensional positions of the galaxies within the 'filament'. 'This technique allowed us to recognize, for the first time, the existence of this filament,' Dr Burns said.

RALPH KAZARIAN
National Science Foundation
1800 G Street
Washington, DC 20550, USA.

